\title{
Mucosal Immune Response in a Case of Sudden Infant Death Syndrome
}

\author{
MAREE GLEESON, ROBERT L. CLANCY, AND ALLAN W. CRIPPS \\ Hunter Immunology Unit, Hunter Area Pathology Service, Royal Newcastle Hospital and Faculty of Medicine, \\ The University of Newcastle, Newcastle, New South Wales, Australia
}

\begin{abstract}
A prospective study to define the normal patterns of development of mucosal immunity in 263 children provided a unique opportunity to study the mucosal immune response in an infant who unexpectedly died from sudden infant death syndrome. The subject initially had a normal pattern of mucosal immune function, which was perturbed after a transient mild upper respiratory tract infection at $3 \frac{1}{2}$ wk of age. After the upper respiratory tract infection, there was an increase in mucosal permeability and the appearance of $\operatorname{IgA}$ and $\operatorname{IgM}$ in saliva. The unusual features in this case were the degree and the duration of the increases in salivary $\operatorname{IgA}$ and $\operatorname{IgM}$ after resolution of the illness. The marked abnormalities suggested a persistent stimulation of the mucosal immune response. The case provides informative data on potential mechanisms of sudden infant death syndrome and supports a role for involvement of upper respiratory tract infection. (Pediatr Res 33: 554-556, 1993)
\end{abstract}

\section{Abbreviations}

SIDS, sudden infant death syndrome

URTI, upper respiratory tract infection

SIDS has been reported to occur after a mild URTI (1-4). As there is no epidemiologic, clinical, pathologic, or microbiologic evidence that favors infection by a particularly virulent pathogen, it is likely that a high degree of stimulation of the immune system may be one important link in the chain of events that culminates in respiratory arrest. Previous studies have suggested that secretory component was absent or reduced in bronchopulmonary epithelium in SIDS (5) and that overstimulation of the mucosal immune response occurs in the respiratory and gastrointestinal tracts (6-9). IL-1 has also been suggested as a mediator between sleep apnea and SIDS during URTI (10). However, the limitations associated with retrospective data collected on postmortem material, as well as the quality of control studies, have presented major difficulties with interpretation of SIDS research.

A prospective study from birth of a cohort of 263 children to determine normal patterns of development of mucosal immunity $(11,12)$ provided an opportunity to study the mucosal immune response in an infant who unexpectedly died from SIDS. We describe in this infant the mucosal immune response after a URTI and postulate that a disturbance in immune regulation and/or mucosal permeability may constitute a link in the chain of events that lead to respiratory arrest.

Received July 7, 1992; accepted January 19, 1993

Correspondence and reprint requests: Dr. Maree Gleeson, Hunter Immunology Unit, Royal Newcastle Hospital, PO Box 664J, Newcastle NSW 2300, Australia.

The study was partially funded by the National Health and Medical Research Council of Australia. The data on the incidence of viral illness in NSW, Australia, were kindly provided by Professor Richard Barry (Department of Virology, University of Newcastle)

\section{MATERIALS AND METHODS}

Clinical history. The female infant was delivered at term by spontaneous vaginal delivery to a 24 -yr-old mother (gravida 4 , para 2) after an uncomplicated pregnancy. She weighed $3620 \mathrm{~g}$ and had Apgar scores of 8 at $1 \mathrm{~min}$ and 10 at $5 \mathrm{~min}$. She was breast-fed until $5 \mathrm{wk}$ of age, but received complimentary formula feeding on the first $2 \mathrm{~d}$ of life, and was then totally formula-fed from $5 \mathrm{wk}$ of age. She had not received any childhood vaccinations.

A mild respiratory tract infection (symptoms were a "runny nose" and difficulty breathing) was diagnosed at $3 \frac{1 / 2}{2 k}$ of age by the local doctor. The subject shared a bedroom with two older siblings, one of whom had a prior respiratory tract infection. Her father was atopic, but otherwise there was no family history of specific illness. Both parents smoked more than 10 cigarettes/d. Her mother did not smoke during the pregnancy but resumed smoking immediately after the birth.

The subject was born at the beginning of the Australian autumn and was followed prospectively during the months of March to May. In March, there was an increase in the incidence of mycoplasma pneumonia in the state of New South Wales, whereas respiratory syncytial virus and parainfluenza virus showed normal background incidence during the same period (Australia Communicable Diseases Intelligence Bimonthly statistics).

The infant died at home at $10 \mathrm{wk}$ of age. The postmortem findings confirmed the infant death classification of SIDS, and the examination showed cerebral and pulmonary edema with some shedding of the alveolar lining cells. No acute bronchitis or bronchiolitis was demonstrated.

Immunological investigations. Saliva samples were collected from the SIDS infant $2 \mathrm{~d}$ after birth and during wk 2, 3, 4, 6, and 8 after birth. Salivary $\operatorname{IgA}, \operatorname{IgM}, \operatorname{IgG}$, and albumin were measured by electroimmunodiffusion (13). The reference levels for each analyte were calculated for weekly age groups as the 10th, 50th (median), and 90th percentiles and are represented as shaded areas on Figure 1. Salivary Ig responses during URTI have been previously studied in this cohort of children (14), and the relevant findings have been summarized in this report.

\section{RESULTS}

Albumin. The salivary albumin level was initially low near birth (10th percentile for $2 \mathrm{~d}$ ) but showed a rise and subsequent fall in the 2 nd and $3 \mathrm{rd}$ wk of life (Fig. 1A); the concentrations remained within the normal age-related reference ranges for wk 1 to 3 . The albumin level was significantly increased in the 4th wk, being 7 times higher than the age-related median level. The albumin levels in the 6th and 8th wk declined but remained above the 90th percentile for each age group.

In the control study examining salivary protein responses during URTI (14), the geometric mean albumin levels within any individual child did not differ between periods of URTI and noninfection periods. 

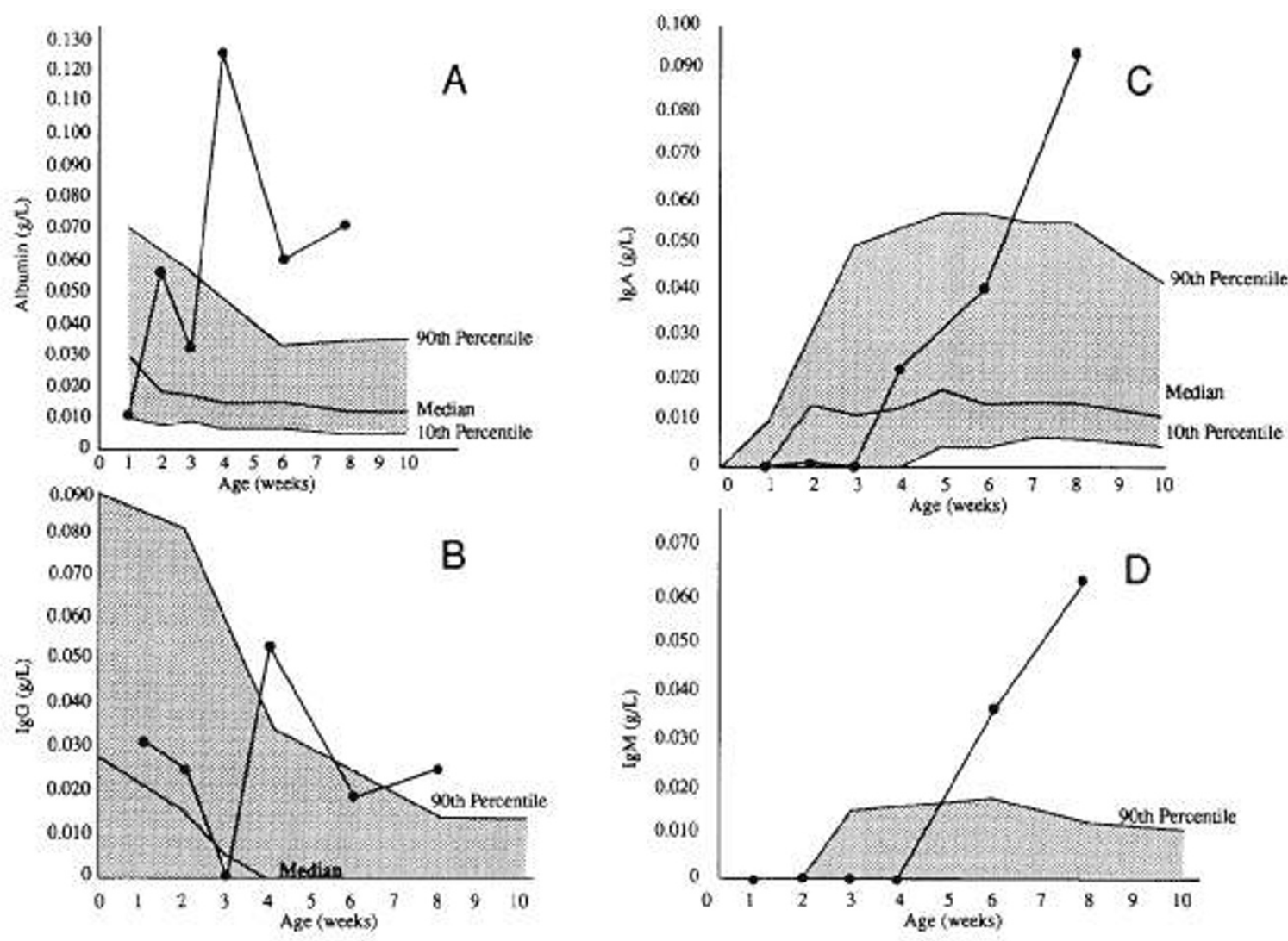

Fig. 1. Albumin $(A), \operatorname{IgG}(B), \operatorname{IgA}(C)$, and $\operatorname{IgM}(D)$ concentrations in saliva collected from birth to 8 wk of age in an infant who died of SIDS. Age-related reference ranges are represented as shaded areas.

$\operatorname{Ig} G$. The salivary $\operatorname{IgG}$ level was within normal age limits at birth $(0.031 \mathrm{~g} / \mathrm{L})$ and decreased to a nondetectable level at $3 \mathrm{wk}$ of age (Fig. $1 B$ ). The $\mathrm{IgG}$ level rose at 4 wk of age to $0.054 \mathrm{~g} / \mathrm{L}$, a level above the 90 th percentile for this age group. The IgG level declined in the 6th wk but at $8 \mathrm{wk}$ was again above the 90 th percentile for this age.

In the control study (14), IgG was detected in saliva more frequently in samples collected during URTI (89\%) than during noninfection periods $(53 \%)$, but the concentrations did not exceed the 90th percentile for age for any subject.

$\operatorname{Ig} A$. Low $(0.009 \mathrm{~g} / \mathrm{L})$ or nondetectable levels of $\mathrm{IgA}$ were measured in the saliva for the first 3 wk of life (Fig. 1C). The IgA level rose in the 4 th wk of life $(0.022 \mathrm{~g} / \mathrm{L})$ and continued to rise in samples collected in the 6th and 8 th wk to a level $(0.093$ $\mathrm{g} / \mathrm{L}) 5$ times higher than the age-related median level for $8 \mathrm{wk}$ of age.

In the control study (14), elevations of salivary IgA were observed during 18 of 20 URTI periods studied, and the IgA returned to noninfection mean levels within $10 \mathrm{~d}$ of disappearance of symptoms. The IgA peak level during URTI periods in three children studied under 6 mo of age did not exceed 0.020 $\mathrm{g} / \mathrm{L}$.

$\operatorname{Ig} M$. IgM was not detected in the saliva samples collected in the first 4 wk of life (Fig. $1 D$ ). IgM was detected in the samples collected in the 6th and 8th wk of life, at levels above the 90th percentile for age, and at $8 \mathrm{wk}$ of age was 10 times higher than the age-related median level.

In the control study (14), there was no significant association between URTI and the detection of IgM in saliva.

\section{DISCUSSION}

We report results of investigations of mucosal immunity in an infant who died of SIDS. The cohort of 262 healthy infants had been prospectively studied from birth for $5 \mathrm{y}$, enabling a precise definition of normal patterns of development of mucosal immunity and factors that alter the ontogeny (11-13), including the influence of URTI (14). Analysis of saliva protein levels in the SIDS infant demonstrated a prolonged period of increased mucosal permeability and an exaggerated and prolonged mucosal immune response after an URTI, both of which persisted until the assessment period $2 \mathrm{wk}$ before the infant's death.

In the immediate postnatal period, the detection of $\mathrm{IgG}$ and high levels of albumin reflect a normal transient physiologic state of increased mucosal permeability (15). The subject of this report initially had a normal pattern of mucosal function, with a rapid disappearance of $\operatorname{IgG}$, a decrease in albumin levels in saliva, and an absence of detectable IgA and IgM. The normally evolving saliva protein profile was perturbed after a transient mild respiratory tract infection. The reappearance of $\lg G$ and the increase in saliva albumin levels from the time of the URTI reflects an increase in mucosal permeability, which has been noted in normal infants after antigenic challenge, including infection of the respiratory tract (14).

The appearance of IgM and an increase in IgA in saliva is a normal event after URTI (14). The unusual features, unique in our experience in the SIDS infant, were both the degree and the duration of the increases in the salivary Ig levels. We have prospectively followed normal infants with URTI and commonly noted minor increases in $\operatorname{IgA}, \operatorname{IgG}$, and $\operatorname{IgM}$, but they have been small in amount and have always returned to normal levels within $10 \mathrm{~d}$ of disappearance of clinical symptoms (14). The marked abnormalities in mucosal Ig in the SIDS infant suggested an enhanced immune response, possibly due to increased antigen influx.

Mature mucosal surfaces are down-regulated with respect to immune reactivity to environmental antigen, and control is probably mediated through suppressor $\mathrm{T}$ lymphocytes capable of restricting lymphocyte proliferation (16). Little is known about the maturation of mucosal immune control mechanisms, but an 
apparent oscillatory pattern of salivary IgA levels early in life (13) would be consistent with a period of instability in the first few months of life. The appearance in the saliva of some infants at this time of $\operatorname{IgD}(17)$ and monomeric $\operatorname{IgA}(18)$ further suggests a period of mucosal immaturity. Infants genetically predisposed toward lability in the development of normally rigorous mucosal suppressor mechanisms may account for the abnormal response observed in the SIDS infant.

Previous studies have identified a genetic predisposition (19; 20) and a mild URTI (1-4) as risk factors for SIDS, whereas many of the other risk factors identified (20-29), such as social status, environmental temperature changes, infant overheating, and passive smoking $(4,30-33)$ may secondarily relate to infection or mucosal inflammation. Several of these potentially conditionary risk factors were identified in the SIDS infant.

Recent studies $(20,21)$ have suggested that the pattern of infant feeding is a risk factor, with a decreased incidence of SIDS in breast-fed infants. Formula feeding in early life exerts a significant effect on mucosal function, extending the postnatal period of increased mucosal permeability and causing early activation of mucosal B lymphocytes $(12,15)$. The SIDS subject in this study changed from breast feeding to formula feeding at 5 wk of age, coinciding with the phase of enhanced mucosal immune response. The possible interaction between the effect of introduced food and a concurrent mucosal infection at a critical stage of mucosal maturation requires further study.

The protein changes in saliva were distant from the site of clinical infection. Whether these changes reflect a contiguous infection of oropharyngeal mucosa or a more generalized mucosal change cannot be stated. Nor can a direct or indirect link with respiratory arrest be proven. We would propose, however, the following hypothesis: infants genetically predisposed to transient labile mucosal suppressor mechanisms are particularly at risk should certain environmental events occur in the period of mucosal immaturity. An inappropriate or persistent mucosal immune response to antigen may activate vagal afferent nerve endings or chemoreceptors to induce reflex apnea:

Acknowledgments. The authors thank members of the research team, Professor Stephen Leeder, and Associate Professor Michael Hensley, and in particular Sister Sue Graf for collection of the saliva and Sharron Hall for technical assistance; also, Amanda Beisty for typing this manuscript.

\section{REFERENCES}

1. Shannon DC, Kelly DH 1982 SIDSS and near-SIDS. N Engl J Med 306: 959-965

2. Hoffman JH, Damus K, Hillman L, Krongrad E 1988 Risk factors for SIDS. Results of the National Institute of Health and Human Development SIDS Cooperative Epidemiological Study. Ann NY Acad Sci 533:13-20

3. Nelson EA, Taylor BJ, Mackay SC 1989 Child care practices and the sudden infant death syndrome. Aust Pediatr J 25:202-204

4. Naeye RL 1990 Preventing the sudden infant death syndrome. Pediatr Perinat Epidemiol 4:12-21

5. Ogra PL, Ogra SS, Coppola PR 1975 Secretory component and sudden-infantdeath syndrome. Lancet 2:387-390

6. Thrane PS, Rognum TO, Brandtzaeg P 1990 Increased immune response in upper respiratory and digestive tracts in SIDS. Lancet 1:229-230
7. Forsyth KD, Weeks SC, Koh L, Skinner J, Bradley J 1989 Lung immunoglobulins in the sudden infant death syndrome. Br Med J 298:23-26

8. Stoltenberg L, Saugstad OD, Brandtzaeg P, Rognum TO 1990 SIDS victims show local IgM response in tracheal wall and IgA response in duodenal mucosa. Pediatr Res 28:277(abstr)

9. Stoltenberg L, Saugstad OD, Rognum TO 1992 Sudden infant death syndrome victims show local immunoglobulin $M$ response in tracheal wall and immunoglobulin A response in duodenal mucosa. Pediatr Res 31:372-375

10. Guntheroth WG 1989 Interleukin-1 as intermediary causing prolonged sleep apnea and SIDS during respiratory infections. Med Hypotheses 28:121-123

11. Cripps AW, Clancy RL, Gleeson M, Hensley MJ, Dobson AJ, Firman DW, Wlodarczyk J, Pang GT 1987 Mucosal immuno-competence in man-the first five years of life. Adv Exp Med Biol 216B:1369-1376

12. Cripps AW, Gleeson M, Clancy RL 1991 Ontogeny of the mucosal immune response in children. In: Mestecky J, Blair C, Ogra P (eds) Immunology of Milk and the Neonate. Plenum Press, New York, pp 87-92

13. Gleeson M, Cripps AW, Clancy RL, Husband AJ, Hensley MJ, Leeder SR 1982 Ontogeny of the secretory immune system in man Aust NZ J Med $12: 255-258$

14. Gleeson M, Dobson AJ, Firman DW, Cripps AW, Clancy RL, Wlodarczyk $\mathrm{JH}$, Hensley MJ 1991 The variability of immunoglobulins and albumin in salivary secretions of children. Scand J Immunol 33:533-541

15. Gleeson M, Cripps AW, Clancy RL, Hensley MJ, Dobson AJ, Firman DW 1986 Breast feeding conditions a differential pattern of mucosal immunity. Clin Exp Immunol 66:216-222

16. Clancy RL, Pucci A 1978 Human mucosal lymphocytes-memory for "recall" antigens and non-specific suppression by T-lymphocytes. Adv Exp Med Biol 107:575-582

17. Gleeson M, Cripps AW, Clancy RL, Wlodarczyk JH, Hensley MJ 1987 IgD in infant saliva. Scand J Immunol 26:55-57

18. Cripps AW, Gleeson M, Clancy RL 1989 Molecular characteristics of IgA in infant saliva. Scand J Immunol 29:317-324

19. Hayward J, D'Alessio DJ 1990 SIDS: race as a factor. Wis Med J 89:11-14

20. Mehl AJ, Malcolm LA 1990 Epidemiological factors in postneonatal mortality in New Zealand. NZ Med J 103:127-129

21. Mitchell EA, Scragg R, Stewart AW, Becroft DM, Taylor BJ, Ford RP, Hassall IB, Barry DM, Allen EM, Roberts AP 1991 Results from the first year of the New Zealand cot death study. NZ Med J 104:71-76

22. Holroyd SJ, Madeley RJ, Pearson JC 1989 Postneonatal mortality in the Nottingham Health District 1985-1988. Community Med 11:342-351

23. Rajs J, Hammarquist F 1988 Sudden infant death in Stockholm. A forensic pathology study covering ten years. Acta Paediatr Scand 77:812-820

24. Taylor EM, Emery JL 1988 Trends in unexpected infant deaths in Sheffield. Lancet 2:1121-1123

25. Carpenter RG, Gardner A 1990 Environmental findings and sudden infant death syndrome. Lung 168(suppl):358-367

26. Campbell MJ 1989 Sudden infant death syndrome and environmental temperature: further evidence for a time-lagged relationship. Med J Aust 151:365-367

27. Kock C, Kytir J 1989 Sudden infant death syndrome in Austria. 2: Prevalence pattern and socio-demographic characteristics. Wien Klin Wochenschr 101:539-544

28. Fleming PJ, Gilbert R, Azaz Y, Berry PJ, Rudd PT, Stewart A, Hall E 1990 Interaction between bedding and sleeping position in the sudden infant death syndrome: a population based case-control study. Br Med J 301:85-89

29. Loscher W, Einspieler C, Holzer-Sutter A, Grill D, Moser M, Haidmayer R, Kurz R, Kenner T 1990 Air pollution and sudden infant death in Graz 1982 to 1987 . Wien Klin Wochenschr 102:115-117

30. Kraus JF, Greensland S, Bulterys M 1989 Risk factors for sudden infant death syndrome in the US Collaborative Perinatal Project. Int J Epidemiol 18:113120

31. McGlashan ND 1989 Sudden infant deaths in Tasmania, 1980-1986: a seven year prospective study. Soc Sci Med 29:1015-1026

32. Bulterys M 1990 High incidence of sudden infant death syndrome among northern Indians and Alaska natives compared with southwestern Indians: possible role of smoking. J Community Health 16:185-194

33. Haglund B, Cnattingius S 1990 Cigarette smoking as a risk factor for sudden infant death syndrome: a population-based study. Am J Puivlic Health 80:2932 